\title{
Contribuições da residência em enfermagem na atuação profissional de egressos
}

\author{
Contributions of nursing residency in professional practice of \\ graduates
}

\author{
Camila Severi Zanoni ${ }^{1}$; Maria do Carmo Lourenço Haddad²; Mariana Angela \\ Rossaneis ${ }^{3}$; Marli Terezinha Oliveira Vannuchi'; Raquel Gvozd ${ }^{3}$
}

\begin{abstract}
Resumo
Este estudo objetivou investigar as contribuições da residência em enfermagem na atuação profissional de egressos. Trata-se de um estudo descritivo, com abordagem quantitativa, que teve como participantes de pesquisa enfermeiros que cursaram a residência em enfermagem de uma instituição universitária pública localizada no sul do Brasil. Os critérios de inclusão foram: ter concluído o curso de residência de enfermagem na instituição de estudo (2006 a 2011) e concordar em participar da pesquisa, aprovada pelo Comitê de Ética em pesquisa da instituição tendo CAAE $\mathrm{n}^{\mathrm{o}}$ 0246.0.268.000-11. Os dados foram coletados por meio de formulário on-line, enviado aos egressos via e-mail, com perguntas abertas e fechadas. Até 2011, 90 enfermeiros haviam sido formados nas modalidades de residência em enfermagem, sendo a maioria jovem e recém-formada. Destes, $65(72,2 \%)$ responderam ao formulário, 86,1\% relataram estar trabalhando, divididos em atividades assistenciais (64\%), gerenciais (30\%), de ensino (25\%) e de pesquisa (13\%). Citaram competências adquiridas na residência, como visão crítica, ser agente transformador, atuar em equipe, usar o processo de enfermagem, atuar na gerência, desenvolver pesquisa, atuar com ética, entre outras. Ressaltaram sugestões para possíveis alterações no programa da especialização a fim de suprir as deficiências enfrentadas. A residência mostrouse de grande contribuição para o desenvolvimento da maioria das competências profissionais exigidas do enfermeiro, sendo, portanto, um treinamento em serviço que oferece suporte educacional e práticas diversas, tornando o residente um profissional crítico, capaz de soluções mais resolutivas, além de propiciar a difusão do conhecimento por meio da produção científica.
\end{abstract}

Palavras-chave: Enfermagem. Especialização. Prática profissional. Capacitação em serviço.

\begin{abstract}
This study aimed to investigate the contributions of nursing residence in professional practice of graduates. It is a descriptive study with a quantitative approach, which was to research participant nurses who attended the residence in nursing a public university located in southern Brazil. Inclusion criteria were: having completed the course in nursing residence in the study institution (2006-2011) and agree to participate in the study,
\end{abstract}

1Enfermeira. Especialista em Gerência dos Serviços de Enfermagem pela Universidade Estadual de Londrina- PR, Brasil.

2 Enfermeira. Doutora em Enfermagem. Docente do Departamento de Enfermagem da Universidade Estadual de Londrina, Paraná, Brasil.

3 Enfermeira. Mestre em Enfermagem. Docente do Departamento de Enfermagem da Universidade Estadual de Londrina. Doutoranda em Enfermagem na Universidade Estadual de Maringá, Paraná, Brasil.

4 Enfermeira. Doutora em Saúde Pública. Docente do Departamento de Enfermagem da Universidade Estadual de Londrina, Paraná, Brasil. 
approved by the Research Ethics Committee of the institution having CAAE no 0246.0.268.000-11. Data were collected through an online form, sent to graduates via email, with open and closed questions. By 2011, 90 nurses were trained in the residence arrangements in nursing offered, mostly young and newly formed. Of these, $65(72.2 \%)$ answered the form, $86.1 \%$ reported to be working, divided into care activities $(64 \%)$, management (30\%), education (25\%) and research (13\%). Cited skills acquired in residence as critical view, be a transforming agent, acting as a team, using the nursing process, work in management, develop research, act ethically, among others. Highlighted suggestions for possible changes in the specialization program in order to meet the shortcomings faced. The residence proved to be of great contribution to the development of most of the professional skills required of nurses, and therefore a training service offering educational support and various practices, making the resident a critical professional, capable of resolving more solutions and to provide the dissemination of knowledge through scientific production.

Keywords: Nursing. Specialization. Professional practice. Inservice training.

\section{Introdução}

Os modelos de formação dos profissionais da saúde reportam ao início do século XXI, quando se iniciou a reorganização dos serviços de saúde, em que as principais atuações baseavam-se na promoção da saúde, prevenção e tratamento de agravos (SILVA; SENA, 2008). A recuperação da dimensão cuidadora e a busca da integralidade na atenção à saúde eram desafios propostos para a organização do cuidado no interior dos hospitais (FEUERWERKER; CECILIO, 2007).

Acompanhando este processo, os cursos da área da saúde buscaram aprimorar seus currículos a fim de garantir a formação de profissionais competentes para assistir a população, assim como buscar a melhor forma de gerenciar estes serviços. Portanto, o enfermeiro, ao iniciar um programa de aprimoramento, traz expectativas em torno da sua qualificação e anseia por mudanças pessoais, além de contribuir para a instituição hospitalar (LOPES; MOURA, 2004).

Considerando esses aspectos, o Departamento de Enfermagem de uma universidade estadual localizada no sul do Brasil implantou, em 2006, o Programa Integrado de Especialização em Enfermagem na modalidade Residência, abrangendo cinco subáreas distintas: Enfermagem Médico-Cirúrgica, Neonatal, Saúde da Criança, Perioperatória e Gerência dos Serviços em Enfermagem.

Este programa está estruturado conforme a
Resolução 259/2001 do Conselho Federal de Enfermagem (COFEN) que em seu artigo $2^{\circ}$ regulamenta os Programas de Residência em Enfermagem em âmbito nacional como modalidade de pós-graduação Lato Sensu, destinado a enfermeiros, para desenvolver competências técnico-científica e ética, decorrentes do treinamento em serviço (CONSELHO FEDERAL DE ENFERMAGEM, 2001).

A residência constitui-se em um treinamento em serviço, possibilitando ao estudante a prática junto aos serviços de saúde, fazendo com que o profissional, na maioria das vezes recém-formado, conheça a realidade dos processos de trabalho, assumindo a supervisão de equipes de enfermagem e resolvendo problemas cotidianos, sempre respaldados por profissionais dos serviços e por docentes, além de atentar para práticas gerenciais modernas e respeitar os princípios éticos da profissão. Além do preparo técnico científico, o residente adquire segurança profissional para o desenvolvimento das atividades, se conscientiza da necessidade do aprendizado complementar elegendo prioridades, integra-se com as equipes proporcionando melhores condições de trabalho e elevando o padrão de qualidade do atendimento institucional (HADDAD, 2012).

Considerando que é reduzido o número de instituições que disponibilizam esta modalidade de residência no país, este estudo foi realizado com o objetivo de investigar as contribuições da residência em enfermagem na atuação profissional de egressos. 


\section{Método}

Trata-se de uma pesquisa descritiva, com abordagem quantitativa, que teve como participantes de pesquisa os egressos da residência em enfermagem ofertada por uma instituição universitária pública localizada no sul do Brasil.

Os critérios de inclusão foram: ter concluído o curso de residência de enfermagem na UEL (2006 a 2011) e concordar em participar da pesquisa. Assim, 90 egressos foram convidados a participar do estudo, sendo que $65(72,2 \%)$ responderam ao formulário.

Os dados foram coletados de setembro a novembro de 2012, por meio de formulário on-line enviado aos egressos da Residência em Enfermagem, via e-mail, com perguntas abertas e fechadas, composto de dados gerais de caracterização da população e relacionados à trajetória profissional, capacitação profissional e dados sobre a residência em enfermagem cursada.

Os e-mails dos egressos foram solicitados aos docentes de cada área ofertada pela Residência em Enfermagem e também por meio de redes sociais. Os participantes foram informados a respeito da justificativa e do objetivo do estudo, da liberdade de recusa da pesquisa ou da retirada da mesma durante qualquer momento.

Os dados foram digitados no programa Excel 2010 e analisados por porcentagens simples. Esta se constitui em uma pesquisa isolada, aprovada pelo Comitê de Ética em Pesquisa da instituição onde o estudo foi realizado, tendo CAAE $n^{\circ}$ 0246.0.268.00011, com parecer 297/2011.

\section{Resultados}

A residência em enfermagem da instituição em estudo especializou, de 2006 a 2011, 90 enfermeiros e além destes, cinco desistiram antes da conclusão do curso.

Com relação ao estado civil dos participantes, 40 relataram serem solteiros, 21 casados, três encontramse em união estável e um entrevistado deixou de responder a esta questão.

A idade predominante corresponde a 27 anos, com $23,1 \%$ do total, seguida por 25 anos, com 15,4\%.

A maioria dos egressos $(43,1 \%)$ residia em Londrina antes de iniciar esta pós-graduação, seguida por aqueles que moravam no Estado de São Paulo $(21,5 \%)$ e Maringá-PR (13,8\%). Os demais vieram de cidades do interior do Estado e uma egressa veio de Belém-PA.

Após a conclusão da Residência, a maioria permaneceu em Londrina (46,1\%), 20\% passaram a morar no Estado de São Paulo, 12,4\% estão nas cidades próximas de Londrina, 10,8\% em Maringá e os demais (10,7\%) distribuem-se entre os estados de Santa Catarina, Mato Grosso do Sul, Distrito Federal, Curitiba e na Áustria.

No momento da coleta de dados, $86,1 \%$ estavam trabalhando, sendo que apenas quatro egressos realizavam atividade fora da área da enfermagem, sendo um empresário do ramo alimentício, um residia no exterior e ainda não tinha permissão para exercer a profissão, outro era proprietário de loja de sapatos femininos e outro era gerente de qualidade de uma empresa de manutenção de equipamentos hospitalares.

A atividade assistencial foi considerada predominante no emprego, com $64 \%$ das respostas, seguida pela atividade gerencial (30\%), de ensino (25\%), pesquisa $(13 \%)$ e outras atividades correspondem a $2 \%$. Além disso, $8 \%$ dos entrevistados não atuavam como enfermeiros no momento da pesquisa. Cabe ressaltar que o entrevistado poderia assinalar mais de um item deste assunto, podendo a somatória das respostas ultrapassar 100\%.

No que se refere à remuneração, $8 \%$ alegaram receber até dois salários mínimos, $20 \%$ de dois a três, os egressos que recebiam de três a quatro e de quatro a cinco salários correspondiam a $26 \%$ cada, e os que recebiam acima de cinco salários equivaliam a $11 \%$. Os $9 \%$ restantes não trabalhavam no momento pesquisado, pois realizavam pós-graduação com bolsa de estudos. 
Entre os 14 participantes da Enfermagem MédicoCirúrgica, 11 trabalhavam na área no momento em que a pesquisa foi realizada, duas estavam cursando pósgraduação com bolsa, e uma não atuava, pois residia no exterior e ainda não tinha permissão para exercer a profissão.

Já na área de Gerência dos Serviços de Enfermagem, das 23 egressas, 18 possuíam vínculo empregatício no momento pesquisado, as cinco restantes cursavam pósgraduação com bolsa.

$\mathrm{Na}$ Neonatologia, as oito egressas relataram estar trabalhando, assim como as 14 egressas da área de Saúde da Criança, sendo que uma destas não atuava na Enfermagem.
Por fim, na Enfermagem Perioperatória, das cinco egressas participantes, todas relataram estar trabalhando, entretanto, duas não atuavam como enfermeiras.

Com relação à associação a alguma Entidade de Classe, 64\% (36) eram associados apenas ao Conselho Regional de Enfermagem (COREN). Entre os demais, além do COREN, 16\% (nove) estavam associados também ao Sindicato, oito (14\%) à Associação dos Especialistas, quatro (7\%) à Associação Brasileira de Enfermagem (ABEn) e três (5\%) a outra entidade. Nesta questão, também era permitido ao entrevistado assinalar mais de um item.

Sobre a educação continuada, 49 (75,4\%) possuem outro curso de pós-graduação, concluído ou em andamento, conforme visualizado na tabela 1 .

Tabela 1 - Distribuição dos egressos segundo especializações realizadas além da residência em universidade pública, 2013.

\begin{tabular}{cccccc}
\hline Residência & $\begin{array}{c}\mathbf{N}^{\circ} \text { de } \\
\text { questionários } \\
\text { respondidos }\end{array}$ & Mestrado & $\begin{array}{c}\text { Especiali- } \\
\text { zação }\end{array}$ & $\begin{array}{c}\text { Mestrado e } \\
\text { Especializa-ção }\end{array}$ & Doutorado \\
\hline Perioperatória & 5 & 2 & 1 & 0 & 0 \\
$\begin{array}{c}\text { Médico- } \\
\text { Cirúrgica }\end{array}$ & 14 & 4 & 4 & 2 & 1 \\
$\begin{array}{c}\text { Gerência de } \\
\text { Serviços de } \\
\text { Enfermagem } \\
\text { Saúde da } \\
\text { Criança }\end{array}$ & 23 & 9 & 0 & 11 & 0 \\
$\begin{array}{c}\text { Neonatologia } \\
\text { Neonato }\end{array}$ & 8 & 8 & 2 & 0 & 0 \\
\hline
\end{tabular}

Fonte: Os autores.

Os egressos que não cursaram outra especialização além da residência alegaram falta de tempo, falta de necessidade, mudança de país, problemas familiares, falta de liberação pela instituição de trabalho, dificuldade financeira e falta de interesse.

Entre os egressos, 95,4\% participaram de eventos de atualização. Na Residência em Enfermagem Perioperatória, todos os egressos responderam ao questionário eletrônico participaram destes eventos, tendo obtido duas premiações em trabalhos apresentados: $1^{\circ}$ lugar em um evento local e $1^{\circ}$ lugar em evento nacional. Dos trabalhos produzidos durante a residência, quatro foram submetidos a periódicos com QUALIS/CAPES B2, um foi submetido a periódico $\mathrm{B} 1$, e dois a periódicos A2 e B3, cada.

$\mathrm{Na}$ Enfermagem Médico-Cirúrgica, 12 participaram destes eventos, onde um foi palestrante e houve três premiações: $1^{\circ}$ lugar em um evento local, $1^{\circ}$ lugar em evento nacional e menção honrosa em evento nacional. Com relação aos periódicos aos quais os trabalhos foram submetidos, sete foram 
encaminhados para periódicos classificados como B2, três B1, um B4 e um B5.

$\mathrm{Na}$ Gerência de Serviços de Enfermagem, 23 participaram destes eventos. Treze foram organizadores de eventos, 17 palestrantes, e ocorreram premiações: $2^{\circ}$ e $3^{\circ}$ lugares em evento nacional e menção honrosa em evento nacional. Com relação aos periódicos aos quais os trabalhos foram submetidos, 29 foram encaminhados para periódicos com QUALIS/CAPES B2, 25 para B1, 11 trabalhos para periódicos $\mathrm{A} 2,10$ para $\mathrm{B} 3$, três trabalhos para periódicos B4 e um para periódico A1.

$\mathrm{Na}$ Enfermagem em Saúde da Criança, 14 egressas participaram destes eventos, sendo que uma foi palestrante e uma organizadora, havendo três premiações: $1^{\circ}$ lugar em um evento local e $3^{\circ}$ lugar em evento nacional. Com relação aos periódicos aos quais os trabalhos foram submetidos, dez foram submetidos para periódicos classificados como B2, nove para B1, e um para A2, B3 e B4, cada.

$\mathrm{Na}$ Enfermagem em Neonatologia, seis participaram destes eventos, sendo que um atuou como palestrante e dois foram organizadores. Com relação aos periódicos aos quais os trabalhos foram submetidos, dez foram encaminhados para periódicos classificados como B1, seis para B2, dois para A2 e um para B5.

Assim, entre os eventos de atualização, prevaleceram os encontros locais $(84,6 \%)$, seguido por cursos com mais de 30 horas $(73,8 \%)$, congressos nacionais $(70,8 \%)$, e congressos locais $(69,2 \%)$ e encontros internacionais $(69,2 \%)$. Os congressos e encontros regionais foram os que apresentaram menor participação $(63,1 \%$, cada).

Observou-se também que $80 \%$ dos egressos possuem produções publicadas ou aceitas para publicação, onde 52 residentes relataram possuírem artigos científicos publicados ou aceitos para publicação.

Entre os periódicos a que foram submetidos os trabalhos científicos, predominam aqueles com classificação B1 (37), seguido por B2 (36) e A2 (23). Há 15 trabalhos submetidos/publicados em periódicos B5, e 16 em A1.

No que se refere às contribuições da Residência em Enfermagem no desenvolvimento de competências profissionais, explicitadas na Tabela 2, pode-se inferir que uma fragilidade para a Residência Perioperatória reside na atuação na comunidade, enquanto para Neonatologia, está na atuação na gerência e na participação de entidades. $\quad$ Em tempo, a área de Saúde da Criança refere principalmente média contribuição para atuar na gerência, e demonstra fragilidades para atuar no ensino. Para a Residência de Gerência, tanto a atuação na comunidade quanto a participação em entidades apresentaram pouca influência desta pós-graduação. Por fim, para a área de Médico-Cirúrgico as competências que foram menos influenciadas pela residência foram: atuação na comunidade, desenvolvimento de pesquisa e participação em entidades.

Diante das informações apresentadas na Tabela 2, os egressos sugeriram possíveis alterações no programa de residência para suprir as deficiências enfrentadas, tais como: incentivo para a pesquisa e a participação em eventos científicos, aperfeiçoamento dos docentes para supervisão em campos específicos, implantação de encontros multiprofissionais para discussão de temas, elaboração de projetos aplicáveis à unidade de atuação do residente a fim de aperfeiçoar o processo de trabalho e trazer contribuições ao setor, discussões sobre o tema "segurança do paciente", aulas conjuntas com a Residência Médica, desenvolver atividades relacionadas ao controle social, ampliar campo de atuação para a Atenção Básica, realizar um evento científico da residência a cada dois anos, vivenciar campos de estágio externos, incluir discussão sobre os temas "dinâmica de grupo" e "desenvolvimento interpessoal", convidar docentes de referência na área para ministrar aulas, e estender para o segundo ano as aulas de Tronco Comum (união dos residentes de todas as áreas da Enfermagem), que acontece apenas no primeiro ano de residência. 
Tabela 2 - Contribuições da Residência em Enfermagem no desenvolvimento de competências profissionais em universidade pública, 2013.

\begin{tabular}{|c|c|c|c|c|c|c|}
\hline & & $\begin{array}{c}\text { Gerência } \\
(\mathrm{N}=\mathbf{2 3})\end{array}$ & $\begin{array}{c}\text { Saúde } \\
\text { Criança } \\
(\mathrm{N}=14)\end{array}$ & $\begin{array}{l}\text { Neonatologia } \\
(\mathrm{N}=7)\end{array}$ & $\begin{array}{l}\text { Médico } \\
\text { Cirúrgica } \\
(\mathrm{N}=14)\end{array}$ & $\begin{array}{c}\text { Perioperatória } \\
(\mathrm{N}=6)\end{array}$ \\
\hline \multirow{2}{*}{ Ter visão crítica } & Grande & 23 & 12 & 5 & 13 & 6 \\
\hline & Média & - & 2 & 2 & 1 & - \\
\hline \multirow{2}{*}{$\begin{array}{c}\text { Ser agente } \\
\text { transformador }\end{array}$} & Grande & 19 & 11 & 6 & 9 & 4 \\
\hline & Média & 4 & 3 & 1 & 4 & 2 \\
\hline \multirow{2}{*}{$\begin{array}{l}\text { Atuar em } \\
\text { equipe }\end{array}$} & Grande & 18 & 11 & 6 & 11 & 6 \\
\hline & Média & 5 & 3 & 1 & 3 & - \\
\hline \multirow{2}{*}{$\begin{array}{l}\text { Usar processo } \\
\text { Enfermagem }\end{array}$} & Grande & 11 & 14 & 4 & 11 & 4 \\
\hline & Média & 12 & - & 3 & 3 & 2 \\
\hline \multirow{3}{*}{ Atuar gerência } & Grande & 21 & 6 & 1 & 5 & 4 \\
\hline & Média & 2 & 7 & 1 & 6 & 2 \\
\hline & Pequena & - & 1 & 5 & 3 & - \\
\hline \multirow{2}{*}{$\begin{array}{c}\text { Atuar } \\
\text { assistência }\end{array}$} & Grande & 18 & 14 & 7 & 14 & 6 \\
\hline & Média & 5 & - & - & - & - \\
\hline \multirow{3}{*}{ Atuar ensino } & Grande & 16 & 9 & 4 & 8 & 5 \\
\hline & Média & 7 & 3 & 3 & 4 & 1 \\
\hline & Pequena & - & 2 & - & 2 & - \\
\hline \multirow{3}{*}{$\begin{array}{c}\text { Desenvolver } \\
\text { pesquisa }\end{array}$} & Grande & 17 & 8 & 4 & 4 & 4 \\
\hline & Média & 6 & 6 & 3 & 7 & 2 \\
\hline & Pequena & - & - & - & 3 & - \\
\hline \multirow{3}{*}{$\begin{array}{c}\text { Atuar na } \\
\text { comunidade }\end{array}$} & Grande & 2 & 8 & 5 & 4 & 1 \\
\hline & Média & 10 & 6 & 2 & 6 & 3 \\
\hline & Pequena & 11 & - & - & 4 & 2 \\
\hline \multirow{3}{*}{$\begin{array}{l}\text { Participar de } \\
\text { entidades de } \\
\text { classe }\end{array}$} & Grande & 1 & 4 & - & - & - \\
\hline & Média & 7 & 4 & - & 4 & 4 \\
\hline & Pequena & 15 & 6 & 7 & 10 & 2 \\
\hline \multirow{3}{*}{$\begin{array}{l}\text { Investir na } \\
\text { educação } \\
\text { continuada }\end{array}$} & Grande & 20 & 13 & 6 & 7 & 5 \\
\hline & Média & 2 & 1 & - & 5 & 1 \\
\hline & Pequena & 1 & - & 1 & 2 & - \\
\hline \multirow{2}{*}{$\begin{array}{l}\text { Aprender } \\
\text { iniciativa } \\
\text { própria }\end{array}$} & Grande & 18 & 14 & 7 & 12 & 6 \\
\hline & Média & 5 & - & - & 2 & - \\
\hline \multirow{2}{*}{ Atuar com ética } & Grande & 21 & 14 & 7 & 14 & 6 \\
\hline & Média & 2 & - & - & - & - \\
\hline
\end{tabular}

Fonte: Os autores.

\section{Discussão}

A busca por essa modalidade de especialização atrai principalmente enfermeiros recém-formados, como foi possível perceber por meio da caracterização dos egressos. Neste sentido, uma pesquisa realizada com egressos das residências de Centro Cirúrgico e de Terapia Intensiva de uma dada instituição revelou que no curso da graduação o tempo para o desenvolvimento das práticas é insuficiente, considerando-se o propósito de se tornarem profissionais diferenciadas, o que levou tais enfermeiros a buscar uma especialização na modalidade residência. Tal raciocínio se desenvolve no momento em que os recém-formados se veem tendo que competir, incansavelmente, por uma vaga no mercado de trabalho, que vem exigindo uma gama cada vez maior de competências específicas (SILVA, 2013).

Ainda em relação à faixa etária jovem dos egressos participantes desta pesquisa, cabe destacar que esta fase da vida possibilita uma grande aquisição de conhecimentos e retorno dos investimentos para a 
profissão e para a sociedade, sendo de grande interesse dos órgãos de fomento, que buscam a formação de jovens doutores (BRAQUEHAIS; ARAÚJO; FERNANDES, 2005).

Outro aspecto que merece destaque é a competitividade do mercado de trabalho enfrentada por enfermeiros recém-formados, neste sentido, um estudo realizado em Minas Gerais, Brasil, chama atenção para a ampliação do número de vagas de graduação em enfermagem que aconteceu a partir de 2001 e, em função disso, o aumento do número de ingressos, o que refletiu no número de concluintes entre 2005 e 2008. Tal fato remete a preocupação em relação à oferta de vagas de trabalho para estes profissionais graduados (SILVA et al., 2012).

Nesta perspectiva, um estudo realizado com 114 egressos de um curso de graduação em enfermagem identificou que apenas $55,76 \%$ destes haviam ingressado no mercado de trabalho atuando como enfermeiros, evidenciando a alta competitividade existente. O estudo revela ainda que $62,50 \%$ dos egressos estavam cursando ou haviam cursado pós-graduação, na busca de qualificação que os tornem mais competitivos.

Para tanto a residência, por constituir-se em uma modalidade de formação continuada, que tem como essência o treinamento em situações reais de trabalho vinculado a uma discussão acadêmica, é uma formação de excelência para qualificar, especializar e atualizar enfermeiras, além de facilitar a transição de enfermeiro recém-graduado para especialista (SILVA, 2013).

Esta se torna uma maneira de selecionar os profissionais qualificados para atuarem no mercado de trabalho, sendo a residência um título que favorece este ingresso, constatado umestudo, onde $86,1 \%$ dos egressos relataram estar trabalhando no momento da coleta de dados, sendo este um índice satisfatório. Ressalta-se que a residência, em grande parte das universidades, possibilita o acesso dos estudantes a outras organizações no decorrer do curso, entre elas as privadas, o que favorece a realização de um network com consequentes contratações futuras destes profissionais. Cabe destaque o fato de que a principal absorção dos pós-graduandos no mercado de trabalho se dá em instituições privadas (BRAQUEHAIS; ARAÚJO; FERNANDES, 2005).

Os resultados apontam ainda que as áreas de atuação dos egressos estão voltadas tanto para a assistência como para a gerência, ensino e pesquisa, o que demonstra ser a residência suporte teórico e prático que permite ao residente crescimento profissional e pessoal individualizado, considerando que são oferecidas oportunidades para que este se torne um profissional competente e capacitado para as exigências do mercado de trabalho.

Semelhante a esta investigação, um estudo com 26 egressos de residência de enfermagem em Unidade de Terapia Intensiva (UTI) verificou o tipo de atividade que as profissionais desempenhavam no momento da coleta de dados, sendo que $56 \%$ referiram atuar na assistência da UTI e gerenciamento, $16 \%$ no ensino e pesquisa, $16 \%$ na assistência em UTI e ensino e pesquisa e 12\% referiram o desenvolvimento de outras atividades (SANTOS; WHITAKER; ZANEI, 2007).

Tais dados evidenciam quea residência ofereceaporte técnico e científico para que os enfermeiros especialistas atuem em diferentes campos, sendo capacitados para desenvolverem atividades assistenciais, gerenciais, de ensino e pesquisa com competência e qualidade.

Todo este conhecimento e competências adquiridas podem refletir em recompensa financeira, destacada pelos egressos que, em sua maioria, recebem acima de três salários mínimos mensais. Segundo Silva (2013), a maioria dos profissionais qualificados recebe salários considerados acima da média dos recebidos por enfermeiros recém-formados. Dessa maneira, a melhoria na condição financeira ocorre rapidamente à medida que estes profissionais saem do anonimato natural de recém-formado, tornando-se profissionais especializados, reconhecidos e valorizados pelo mercado de trabalho (SILVA, 2013).

Quanto à busca por outras especializações além da residência, observados neste estudo, uma pesquisa realizada com 150 enfermeiros de uma subdivisão do distrito de Lisboa mostrou que os participantes foram motivados a buscar uma especialização para adquirir 
novos conhecimentos e competências, progredir profissionalmente, enriquecer o curriculum vitae, ter um melhor desempenho no trabalho, adquirir e aprender conhecimentos úteis para o dia-a-dia, conseguir um trabalho melhor remunerado, entre outros motivos (FERREIRA, 2013). Cabe destacar que a residência incentiva à busca por aprimoramento científico, que resulta em maior qualificação profissional, fato que pode ter levado a maioria dos egressos a buscarem outras especializações, mestrado e doutorado.

Este fato também se deve pelo maior incentivo das instituições empregadoras para que seus colaboradores se especializem constantemente a fim de manterem um padrão de qualidade, garantindo sua presença no mercado cada vez mais competitivo que possui usuários conscientes e exigentes dos seus direitos. Para tanto, as instituições passaram a direcionar a necessidade de formar profissionais com novo perfil, capaz de assumir responsabilidades, propor mudanças e tomar decisões, buscando resolutividade em situações complexas (SILVA, 2013).

Ainda, a formação especializada poderá ser encarada como um investimento que facilita o desenvolvimento de competências, compensando as qualificações das organizações e do seu respectivo capital humano. Este fato poderá contribuir para especificidade e inovação institucional, através de um capital humano altamente qualificado, oferecendo aos mercados um produto final, com padrões elevados de qualidade (FERREIRA, 2013).

Atrelado a busca por especializações, observouse que os egressos participaram de eventos científicos mesmo após a conclusão da residência, o que também os torna atualizados quanto aos problemas de saúde da população e as possíveis formas de enfrentamento destes. Além disso, eventos científicos tem a finalidade de produzir conhecimento e divulgá-lo à comunidade, a fim de propiciar melhoras no processo de trabalho.

Ressalta-se que a residência possui importante papel no incentivo dos estudantes para a incorporação do meio científico em sua prática profissional. No decorrer do curso, os residentes de enfermagem da instituição em questão são estimulados a desenvolver pesquisas científicas que são apresentadas em eventos e enviadas para publicação em periódicos nacionais e internacionais, onde $80 \%$ dos egressos relataram terem trabalhos apresentados em eventos ou publicados em periódicos científicos.

A enfermagem vem, gradativamente, tornando-se uma profissão socialmente reconhecida e avançando na produção de conhecimentos próprios. Neste sentido, a pesquisa vem sendo estimulada principalmente nos cursos de pós-graduação. Esta, além de subsidiar o desenvolvimento de competências quantitativa e qualitativa da enfermagem, busca soluções para os problemas do cuidar e agrega a este contexto a expectativa de produzir impacto e mudanças na qualidade da assistência nos serviços prestados a população (GUARIENTE, 2006).

A formação do residente em pesquisa cientifica é fundamental para que o aluno realize suas atividades com embasamento científico, e promova transformações em sua prática profissional, além de prepará-lo para o ingresso em programas de pós-graduação stricto senso. Esse tipo de capacitação eleva a qualidade da assistência de enfermagem e forma profissionais bem preparados para o exercício da prática profissional, com condições de atender a demanda do mercado de trabalho onde a tecnologia exige maior conhecimento e especialização (HADDAD, 2012).

Destaca-se que este prepara para o ingresso em programas de pós-graduação stricto senso tem produzido frutos, sendo constatado neste estudo que além de outras especializações, os egressos buscam formação em nível de mestrado e doutorado.

Tal modalidade resulta na aquisição de competências profissionais relatadas pelas egressas deste estudo, como visão crítica, ser agente transformador, atuar com ética, atuar em equipe, usar o processo de enfermagem, atuar na gerência, entre outras. O que implicam em mudanças na natureza e no processo de trabalho dos enfermeiros, através de múltiplos processos transicionais, que originam e resultam em mudanças na vida e nos ambientes das pessoas envolvidas (MELEIS et al., 2009). 
Em relação às contribuições do programa de residência para a vida profissional e pessoal, egressas de uma residência de enfermagem em UTI referiram que esta especialização foi capaz de gerar autoconfiança, segurança e desenvolvimento da habilidade prática, foi um instrumento ativo para o crescimento pessoal e profissional, oportunizou a conquista de um emprego e contribuiu para a formação teórico-prática não alcançada na graduação (SANTOS; WHITAKER; ZANEI, 2007).

Assim, a Ordem dos Enfermeiros de Portugal publicou em 2011, as funções comuns a todos os enfermeiros detentores do título de enfermeiro especialista, sendo elas: responsabilidade profissional, ética e legal; melhoria contínua da qualidade, gestão dos cuidados e desenvolvimento das aprendizagens profissionais, melhoria contínua da qualidade, gestão dos cuidados, desenvolvimento das aprendizagens profissionais (ORDEM DOS ENFERMEIROS, 2011).

Portanto, a residência relaciona-se as quatro funções das universidades no sistema educativo, destacadas por Delors et al. (2010), quais sejam: capacitar para o ensino e pesquisa; oferecer formação altamente especializada, de acordo com as necessidades da vida econômica e social; estar aberta a tudo e a todos para responder aos múltiplos aspectos da chamada educação permanente em sentido lato e, cooperar em uma visão global.

Além das competências adquiridas na residência, as egressas sugeriram alterações na estrutura do programa que podem aprimorar o processo de aprendizagem. Neste sentido, a busca pela excelência de um programa exige avaliação contínua a fim de, a partir dos dados reunidos, realizar os ajustes, construções e reformulações no processo ensinoaprendizagem (COLENCI; BERTI, 2012), sendo de fundamental importância que idealizadores desta e de demais modalidades de formação de enfermeiros levem em consideração as avaliações dos estudantes para que se busque o maior nível de qualidade na formação destes profissionais.

\section{Conclusões}

Os resultados alcançados com este estudo demonstram que as competências e habilidades adquiridas na pós-graduação favorecem ao profissional ingressar no mercado de trabalho, que se torna cada vez mais competitivo.

Assim, a residência de enfermagem abordada neste estudo, tal como concebida, vem capacitando enfermeiros para o desempenho de sua função, visando o alcance de melhores resultados na execução dos serviços de enfermagem.

Foi possível verificar que a maioria dos enfermeiros que ingressam na residência é recémformada, em busca de qualificação profissional, o que facilita sua inserção no mercado de trabalho, pois se verificou que $86,1 \%$ dos egressos atuavam na profissão no momento da coleta de dados.

O incentivo ao aprimoramento e produção científica que os residentes recebem durante o curso tem rendido bons resultados, o que contribui para o aprimoramento da prática profissional com consequente qualidade da assistência de enfermagem.

Apesar das sugestões para o aprimoramento da residência, os egressos afirmaram ser esta uma oportunidade para o desenvolvimento da maioria das competências profissionais exigidas do enfermeiro, sendo, portanto, um treinamento em serviço que oferece suporte educacional e práticas diversas, tornando-o um profissional crítico, capaz de soluções mais resolutivas, além de propiciar a difusão do conhecimento por meio da produção científica.

Destaca-se que as competências adquiridas permitem a estes egressos a atuação em diferentes campos, com habilidades técnicas e científicas que tornam estes profissionais diferenciados e altamente competitivos, hábeis a atuarem em importantes cargos do mercado de trabalho. 


\section{Referências}

BRAQUEHAIS, A. R.; ARAÚJO, I. M. A.; FERNANDES, A. F. C. Pós-graduação e mercado de trabalho: possibilidades e incongruências. Revista da Rede de Enfermagem do Nordeste, Fortaleza, v. 6, n. 2, p. 18-25, 2005.

COLENCI, R.; BERTI, H. W. Formação profissional e inserção no mercado de trabalho: percepções de egressos de graduação em enfermagem. Revista Escola Enfermagem USP, São Paulo, v. 46, n. 1, p. 158-66, 2012.

CONSELHO FEDERAL DE ENFERMAGEM. Resolução COFEN - 259/2001. Estabelece padrões mínimos para registro de Enfermeiro Especialista, na modalidade de Residência em Enfermagem. Disponível em: $\quad<$ http://www.portal $\neg$ cofen.com.br/legislacao/ resolucoes $>$. Acesso em: 17 abr.2014.

DELORS， J.; AL-MUFTI, IN'AM; AMAGI, I.; CARNEIRO, R.; CHUNG, F.; GEMEREK, B.; GORHAM, W.; KORNHAUSER, A.; MANLEY, M.; QUERO, M. P.; SAVANÉ, M. A.; SINGH, K.; STAVENHAGEN, R.; SUHR, M. W.; NANZHAO, Z. Educação: um tesouro a descobrir. Relatório para a UNESCO da Comissão Internacional sobre Educação para o Século XXI. Brasília: Unesco, 2010.

FERREIRA, M. R. A. C. De generalista a especialista: motivações para a formação especializada em enfermagem. O caso das organizações de saúde públicas, na sub-região oeste do distrito de Lisboa. 2013. 218 fls. Dissertação (Mestrado em Gestão de Recursos Humanos) - Instituto Superior de Línguas e Administração de Leiria, Liboa. 2013.

FEUERWERKER, L. C. M.; CECILIO, L. C. O. O hospital e a formação em saúde: desafios atuais. Ciência Saúde Coletiva, Rio de Janeiro, v. 12, n. 4, p. 965-971, jul./ago. 2007. Disponível em: <http://www. scielo.br/scielo.php?script=sci arttext\&pid $=\mathrm{S} 1413$ $81232007000400018 \& \operatorname{lng}=$ en\&nrm $=i s o>$. Acesso em: 28 jul. 2014.

GUARIENTE, M. H. D. M. Articulação da atividade investigativa com a prática profissional: processo e produto de enfermeiras assistências apoiadas por um Núcleo de Pesquisa.2006. 325 fls. Tese ( Doutorado em Enfermagem) - Escola de Enfermagem de Ribeirão Preto da Universidade de São Paulo, Ribeirão Preto. 2006.
HADDAD, M. C. F. L. A residencia de enfermagem na formação profissional. Ciência Cuidado e Saúde, Maringá, v. 11, n. 2, jun. 2012. Disponível em: $<\mathrm{http} / / / \mathrm{www}$. revenf.bvs.br/scielo.php? $\quad$ script $=$ sci arttext\&pid=S1677-38612012000200001\&lng=pt\&nr $\mathrm{m}=$ iso $>$. Acesso em: 28 jan. 2014.

LOPES, G. T.; MOURA, C. F. S. O impacto da residência de enfermagem na reconfiguração do perfil do enfermeiro assistencial:1975-2000. Escola Anna Nery Revista Enfermagem, Rio de Janeiro, v. 8, n. 1, p. 39-45, 2004.

MELEIS, A. I.; SAWYER, L. M.; IM, E. O.; MESSIAS, D. K.H.; SCHUMACHER, K. Experiencing transitions: an emerging middle-range theory. In: MELEIS, A. I. Transitions theory: middle-range and situation-specific theories in nursing research and practice. United States of America: Hamilton Printing, 2009. p. 52-64.

ORDEM DOS ENFERMEIROS. Regulamento n. $^{\circ}$ 122/2011. Regulamento das competências comuns do enfermeiro especialista. Diário da República, 2 série, n. 35, 18 fev. 2011. Disponível em: $\quad<$ http://www.ordemenfermeiros.pt/legislacao/ Documents/LegislacaoOE/Regulamento122 2011 CompetenciasComunsEnfEspecialista.pdf $>$. Acesso em: 15 jul. 2014.

SANTOS, V. P.; WHITAKER, I. Y.; ZANEI, S. S. V. Especialização em enfermagem modalidade residência em unidade de terapia intensiva: egressos no mercado de trabalho. Revista Gaúcha de Enfermagem, Porto Alegre, v. 28, n. 2 p.193-9, 2007.

SILVA, K. L.; SENA, R. R. Integralidade do cuidado na saúde: indicações a partir da formação do enfermeiro. Revista Escola Enfermagem USP, São Paulo, v. 42, n. 1, p. 48-56, 2008.

SILVA, K. L.; SENA, R. R.; TAVARES, T. S.; MAAS, L. W. Expansão dos cursos de Graduação em Enfermagem e mercado de trabalho: reproduzindo desigualdades? Revista Brasileira Enfermagem, Brasília, v. 65, n. 3, p. 406-13, 2012.

SILVA, R. M. O. Especialização em enfermagem sob a forma de residência: experiência transicional na trajetória das egressas. 2013. 285 fls. Tese (Doutorado em Enfermagem) - Universidade Federal da Bahia Escola de Enfermagem, Salvador. 2013.

Recebido em: 05 ago. 2014. Aceito em: 22 dez. 2014 